\title{
Effect of Vacancy Formation Energy and Microhardness on the Debye Temperatures of Some a-Phase Alloys
}

\author{
Purushotham Endla \\ Department of Physics, S R Engineering College (Autonomous), Warangal Urban, Telangana, India \\ Email address: \\ psm45456@gmail.com \\ To cite this article: \\ Purushotham Endla. Effect of Vacancy Formation Energy and Microhardness on the Debye Temperatures of Some $\alpha$-Phase Alloys. \\ International Journal of High Energy Physics. Vol. 5, No. 1, 2018, pp. 1-4. doi: 10.11648/j.jihep.20180501.11
}

Received: October 22, 2017; Accepted: November 16, 2017; Published: January 5, 2018

\begin{abstract}
Effect of vacancy formation energy and microhardness on the Debye temperature of some $\alpha$-phase alloys have been carried out on $\alpha$-phase (fcc phase) $\mathrm{Cu}_{1-\mathrm{x}}-\mathrm{Zn}_{\mathrm{x}}$ alloys. The Debye temperatures of $\alpha$-phase $\mathrm{Cu}_{1-\mathrm{x}}-\mathrm{Zn}_{\mathrm{x}}$ alloys have been obtained from X- ray integrated intensities. The integrated intensities have been measured with a Philips 3020 powder diffractometer fitted with a proportional counter using filtered $\mathrm{CuK}_{\alpha}$ radiation at room temperature and have been corrected for thermal diffuse scattering. The Debye temperatures of these alloys have been estimated from the hardness and are compared with those obtained from specific heats, elastic constants and X-ray intensity measurements.
\end{abstract}

Keywords: Vacancy Formation Energy, Microhardness, Debye Temperatures, $\alpha-$ Phase Alloys

\section{Introduction}

An alloy is a combination of two or more elements that results in a substance possessing metallic properties. Elements may combine to form alloys by completely dissolving in each other. The atoms of one element become a part of the space lattice of the other element, thus forming solid solution. If solute atoms take the place of some of the solvent atoms at lattice sites, it is called a substitutional solid solution. A substitutional solid solution is generally formed if the metallic elements are combined. If the solute atoms occupy positions between the lattice sites of the solvent, it is called an interstitial solid solution. Non-metallic elements such as hydrogen, carbon, nitrogen, boron and oxygen form interstitial solid solutions in many of the metals. The solubility of one element in another is governed by three factors.

They are:

(i) relative atomic diameters of solvent and solute atoms

(ii) relative electro negativities of solvent and solute atoms

(iii) relative valence of solvent and solute atoms.

The extent of formation of solid solutions depends on the difference in atomic diameters. It is more favorable when the difference in the atomic diameters of solute and solvent atoms is less than 14 or 15 per cent. The solubility may be limited if the solute and the solvent atoms have large differences in electro negativities. According to the third factor, a metal of higher valence is more likely to be soluble in a metal of lower valence than the reverse. In addition to the three factors discussed above, the solubility in the formation of a solid solution tends to be favoured when the crystal structure of the two metals are of the same type.

A systematic X-ray investigation of vacancy formation energy, microhardness and Debye temperatures of $\mathrm{Cu}_{1-\mathrm{x}}-\mathrm{Zn}_{\mathrm{x}}$ alloys have been discussed in the following sections.

Abrahms and Hsu [1] showed empirically that the Debye temperature of solids can be estimated from the microhardness. Recently osmium received considerable attention because of its remarkable properties. Pantea et al [2, 3] measured elastic constants of osmium and calculated its Debye temperature from low-temperature elastic constants also discussed in the values of Debye temperature of osmium obtained from various methods. Denge et al [4] reported the values of Debye temperature at calculated from theoretically obtained elastic constants data at different applied pressures. Hardness is defined as the resistance offered by the lattice to the motion of dislocations. Hardness is an important solid state property. The chemical forces in a crystal resist the motion of dislocations as it involves the displacement of atoms. This resistance is the intrinsic hardness of a crystal. The hardness can thus be correlated with the strength of interatomic binding in crystals. It correlates with other 
strength dependent parameters like lattice constant, the lattice energy and the elastic properties.

\section{Experimental}

$\mathrm{Cu}_{1-\mathrm{x}} \mathrm{Zn}_{\mathrm{x}}$ alloys with different compositions were prepared from spectroscopically pure $\mathrm{Cu}$ and $\mathrm{Zn}$ metals by melting appropriate quantities in evacuated quartz tubes. During the process of melting the mixture was thoroughly stirred for homogenization. The final compositions have been arrived at after subjecting these alloys to spectroscopic analysis. The powder samples of all the alloys were obtained by gently filing the ingots with jeweller's file. The filings were passed through a 325 mesh screen. All the samples were annealed before making measurements.

X-ray measurements were made with a Philips 3020 diffractometer fitted with a proportional counter using $\mathrm{Cuk} \alpha$ radiation. The $\mathrm{X}$-ray tube was operated at $40 \mathrm{Kv}$ and $25 \mathrm{~mA}$. All measurements were made at room temperature. The XRD patterns of (fast scans) $\mathrm{Cu}_{1-\mathrm{x}} \mathrm{Zn}_{\mathrm{x}}$ alloys are reproduced just to show that only the reflections due to the $\alpha$-phase persist in the alloy diffractogram. The number of reflections ranged from 11 to 13 . For the purpose of measurements of intensities, slow scans were obtained at a scanning speed of $0.5^{\circ}$ per minute. The integrated intensities have been corrected for thermal diffuse scattering using the method of Chipman and Paskin. The absorption correction for a flat sample is angle independent and hence can be included in the scale factor. The porosity effect can also be lumped with the scale factor. The surface roughness effect becomes significant only at $2 \theta<20^{\circ}$; the reflections used in these studies have $2 \theta>20^{\circ}$. The Hardness and Debye temperatures were determined following standard procedures.

\section{Method of Analysis}

\subsection{Debye Tempetature}

For the relative intensity method, the expression for the observed intensities $\mathrm{I}_{0}$ is given by

$$
\mathrm{I}_{0}=\mathrm{CL}_{\mathrm{p}} \mathrm{JF}_{\mathrm{T}}^{2}
$$

where $\mathrm{L}_{\mathrm{p}}$ is the Lorentz-polarization factor, $\mathrm{J}$, the multiplicity factor, $\mathrm{F}_{\mathrm{T}}$ the structure factor and $\mathrm{C}$ is a constant. For a flat powder specimen, the absorption correction is independent of the angle $\theta$, and, hence, is lumped with the constant. The structure factor $\mathrm{F}_{\mathrm{T}}$ in terms of the structure factor $\mathrm{F}$ for the static lattice is given by

$$
\mathrm{F}_{\mathrm{T}}=\mathrm{Fe}^{-\mathrm{M}}
$$

We may also write Eq. (1) as

$$
\mathrm{I} 0=I_{c} e^{-2 B\left(\frac{\sin \theta}{\lambda}\right)^{2}}
$$

$$
\begin{aligned}
& F 2=16 f 2 \text { for } h, k, 1 \text { are all even } \\
& F 2=16 f 2 \text { for } h, k, 1 \text { are all odd } \\
& F 2=0 \text { for } h, k, 1 \text { mixed }
\end{aligned}
$$

Where $\mathrm{f}$ is the atomic scattering factor. For the $\mathrm{Cu}_{1-\mathrm{x}} \mathrm{Zn}_{\mathrm{x}}$ alloy,

$$
<\mathrm{f}>=\mathrm{X}_{\mathrm{Cu}} \mathrm{f}_{\mathrm{Cu}}+\mathrm{X}_{\mathrm{Zn}} \mathrm{f}_{\mathrm{Zn}}
$$

Where $X_{C u}, X_{Z n}$ and $f_{C u}, f_{Z n}$ are the atomic concentrations and atomic scattering factors of $\mathrm{Cu}$ and $\mathrm{Zn}$ respectively.

Values of the atomic scattering factor were taken from Cromer and Waber and International Tables for X-ray Crystallography, and have been corrected for dispersion.

From Eq. (3) it can be seen that $\log \left(\mathrm{I}_{0} / \mathrm{I}_{\mathrm{c}}\right)$ is linearly related to $(\sin \theta / \lambda)^{2}$. By a least square treatment of data, $B$ was determined. From the Debye-Waller theory

$$
\mathrm{B}=\left(\frac{8 \pi^{2}}{3}\right)<\mathrm{u} 2>
$$

for a cubic crystal, where $\left\langle\mathrm{u}^{2}>\right.$ is the mean-square amplitude of vibration. Further, B, may also be expressed as

$$
\mathrm{B}=\left(\frac{6 h^{2}}{m k_{B} T}\right) \mathrm{W}(\mathrm{x})
$$

where $\mathrm{m}$ is the mass, $\mathrm{T}$ the absolute temperature and $\mathrm{h}$ and $\mathrm{k}_{\mathrm{B}}$ are the Planck and the Boltzmann constants respectively. The function $\mathrm{W}(\mathrm{x})$ is given by

$$
\mathrm{W}(\mathrm{x})=\left[\frac{\phi(x)}{x^{2}}+\frac{1}{4 x}\right]
$$

where $ø(x)$ is the Debye function and $x=\theta_{M} / T, \theta_{M}$ being the Debye temperature.

\subsection{Hardness}

Hardness measurements were carried out with a hardness tester fitted with Vicker's pyramidal indenter. The diagonal length of the impression is measured with a digital read out. Microhardness shows load dependence at low loads and becomes load independent at slightly higher loads. Generally the load independence starts around 50 gms. In order to obtain load independent results measurements on all samples were carried out at different loads up to 120 grams. The hardness is calculated from the formula,

$$
\mathrm{H}=1.854 \mathrm{P} / \mathrm{d}^{2}
$$

where $\mathrm{P}$ is the load in grams and $\mathrm{d}$ is the diagonal length in microns. In general, hardness falls as load increases (at low loads) and beyond $50 \mathrm{gms}$ the load dependence is negligible. In all the cases the hardness value at $120 \mathrm{gms}$ is taken as the true microhardness. 


\section{Results and Discussion}

The Debye temperature of a solid can be calculated from the formula

$$
\theta_{\psi}=\mathrm{CV}^{1 / 6} \mathrm{M}^{-1 / 2} \psi^{-1 / 2}
$$

Plendl et al [5] have pointed out that the microhardness (H) of a solid is dimensionally reciprocal to the compressibility and for isostructural material $\psi$ is proportional to $\mathrm{H}^{-1}$. Substituting for $\psi$ in Eq. 10, the following relation is obtained for Debye temperature $\left(\theta_{\mathrm{H}}\right)$ in terms of hardness

$$
\theta_{\mathrm{H}}=\mathrm{C}^{\prime} \mathrm{V}^{1 / 6} \mathrm{M}^{-1 / 2} \mathrm{H}^{1 / 2}
$$

where $\mathrm{C}^{\prime}$ is a new proportionality constant. Abrahams and Hsu [1] verified this relation for several chalcopyrites and used the relation to estimate the Debye temperatures of some chalcopyrites for which the hardness was known and Debye temperatures by other methods were not available. Seigal [6] also used this relation to obtain the values of Debye temperatures of several carbides and nitrides of transition elements. Recently Gopi Krishna and Kishan Rao [7] and Shankarnarayana [8] verified this relation for severral hep metals.

In the present investigation measerements have been carried out on the micro- hardness of all the $\mathrm{Cu}_{1-\mathrm{x}}-\mathrm{Zn}_{\mathrm{x}}$ alloys. The motivation for this study is to verify the empirical method developed by Abraham and Hsu [1] for the calculation of Debye temperature from microhardness. It was felt that measurements of microhardness on $\mathrm{Cu}_{1-\mathrm{x}} \mathrm{Zn}_{\mathrm{x}}$ alloys, which have been used in the measurements of the X-ray Debye temperature, would help in verifying method of Abraham and Hsu [1].

The load variation of microhardness for $\mathrm{Cu}_{0.60}-\mathrm{Zn}_{99.60}$ alloy is shown in Figure 1. In all the cases the hardness decreases steeply as the load increases, but load variation becomes negligible above a load of $75 \mathrm{gm}$. The values of hardness at a load of $120 \mathrm{gm}$ are given in Tables 1 for cubic phase. The Equation 3 has been tested on $\mathrm{Cu}_{1-\mathrm{x}}-\mathrm{Zn}_{\mathrm{x}}$ alloys by using the hardness data given in Table 1 and the data on Debye temperatures obtained in this work by the X-ray method. For this purpose the constant $C^{\prime}$ has been chosen to be $5 \times 10^{-7}$. This value of the constant is used for calculating the Debye temperature of $\mathrm{Cu}_{1-\mathrm{x}}-\mathrm{Zn}_{\mathrm{x}}$ alloys from the microhardness data. These values are given in Tables 1 for fcc phase, in which are also included the X-ray values of Debye temperatures obtained in the present work for comparison. The microhardness values are also plotted against composition in Figure 2 for fcc phase alloys. The value of hardness for any material depends on the condition of the sample under which it is prepared, the impurity content present in the sample and the load at which the value of hardness is measured. All these factors contribute to the uncertainties in the value of the hardness. Considering these factors, there is very good agreement between the Debye temperature values calculated from the hardness and those obtained experimentally from Xray intensities. The hardness measurement is a simple test and it needs small-sized samples. Further, it is a nondestructive measurement. The present calculations show that in alloy samples where only hardness measurements are available, a reasonable estimate of the Debye temperature can be made by using Equation 3 .

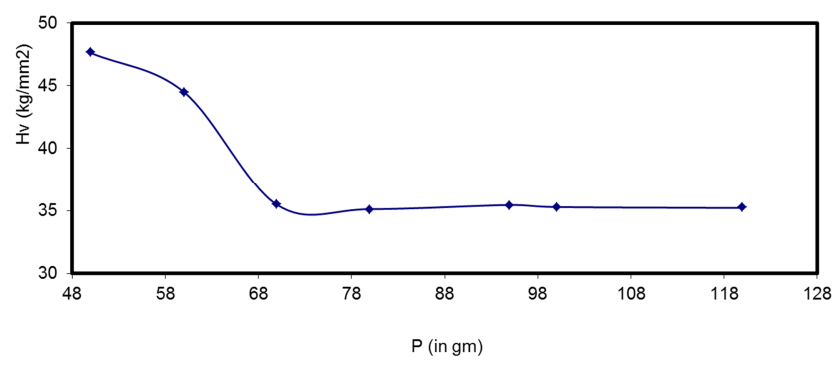

Figure 1. The load variation of micro hardness for $\mathrm{Cu}_{94.15} \mathrm{Zn}_{5.85}$ alloys.

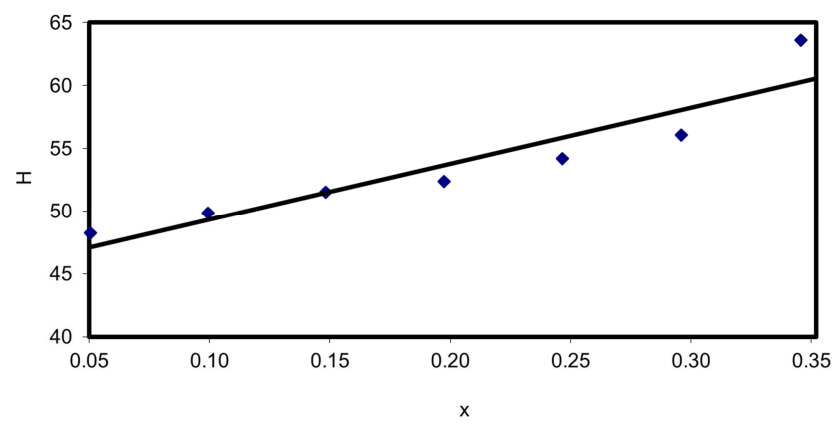

Figure 2. Plots of micro hardness (H) vs composition (x) for fcc phase $C u_{1-x^{-}}$ $Z n_{x}$ system.

According to the Kopp-Neumann relation, the Debye temperature of a binary alloy is given by

$$
\theta^{-3}=(1-\mathrm{x}) \theta_{1}^{-3}+\mathrm{x} \theta_{2}^{-3}
$$

where $\theta$ is the Debye temperature of the alloy containing an atomic concentration $\mathrm{x}$ of the solute; $\theta_{1}, \theta_{2}$ are the Debye temperatures respectively of the pure solvent metal and solute metal. The values of Debye temperature for the $\mathrm{Cu}_{1-\mathrm{x}^{-}}$ $\mathrm{Zn}_{\mathrm{x}}$ alloys calculated from the Kopp-Neumann relation are included in table 1 . The experimental values of of $\theta_{M}$ are systematically less than the calculated values of Debye temperature from Kopp-Neumann relation. This could be due to the fact that the Kopp-Neumann relation does not take into account the defect state of the sample under investigation.

The values of vacancy formation energy are useful in understanding the diffusion mechanism in substitutional solid solutions as the vacancy mechanism is the dominant mechanism for diffusion in most pure metals and substitutional solid solutions. As such, an attempt has been made to estimate the values of energy of vacancy formation ( $\left.\mathrm{E}_{\mathrm{f}}\right)$ for $\mathrm{Cu}_{1-\mathrm{x}}-\mathrm{Zn}_{\mathrm{x}}$ alloys.

Glyde [9] derived the following relation between the energy of vacancy formation $\left(\mathrm{E}_{\mathrm{f}}\right)$ and the Debye temperature $(\theta)$ of a solid;

$$
E_{f}=A(k / \hbar)^{2} M \theta^{2} a^{2}
$$

$\mathrm{a}$ is the interatomic spacing, $\mathrm{A}$ a constant shown to be equal 
to $1.17 \times 10^{-2}, \mathrm{M}$ the atomic weight and $\mathrm{h}$ and $\mathrm{k}$ are the Plank's and the Boltzmann's constants respectively. Glyde [9] recommended the use of X-ray based values for use in Eq. (12). The validity of Eq. (12) was verified for a number of fcc, bcc and hep metals [10-13]. Therefore, the X-ray
Debye temperatures obtained in the present work have been used to estimate vacancy formation energies for $\mathrm{Cu}_{1-\mathrm{x}}-\mathrm{Zn}_{\mathrm{x}}$ alloys. The values estimated vacancy formation energies for $\mathrm{Cu}_{1-\mathrm{x}}-\mathrm{Zn}_{\mathrm{x}}$ alloys are also included in Table 1 .

Table 1. Values of hardness $(H)$ and Debye temperature $(\theta)$ for some $f c c$ phase $C u_{1-x} Z n_{x}$ alloys.

\begin{tabular}{|c|c|c|c|c|c|}
\hline Alloy & $\mathrm{H}\left(\mathrm{Kg} / \mathrm{mm}^{2}\right)$ & $\theta_{\mathrm{H}}(\mathrm{K})$ from Eq. (3) & $\theta_{M}(K)$ & $\theta(\mathrm{K})$ From Kopp-Neumann relation & $E_{f}(e V)$ \\
\hline $\mathrm{Cu}_{94.15} \mathrm{Zn}_{5.85}$ & 48.34 & 310 & 306 & 305 & 1.662 \\
\hline $\mathrm{Cu}_{91.25} \mathrm{Zn}_{8.75}$ & 49.74 & 307 & 303 & 296 & 1.519 \\
\hline $\mathrm{Cu}_{84.35} \mathrm{Zn}_{15.65}$ & 51.62 & 302 & 299 & 289 & 1.442 \\
\hline $\mathrm{Cu}_{81.45} \mathrm{Zn}_{18.55}$ & 52.48 & 300 & 292 & 282 & 1.340 \\
\hline $\mathrm{Cu}_{74.55} \mathrm{Zn}_{25.45}$ & 53.26 & 295 & 286 & 275 & 1.251 \\
\hline $\mathrm{Cu}_{71.50} \mathrm{Zn}_{28.50}$ & 55.23 & 291 & 281 & 270 & 1.176 \\
\hline $\mathrm{Cu}_{64.65} \mathrm{Zn}_{35.35}$ & 64.12 & 273 & 276 & 264 & 1.104 \\
\hline
\end{tabular}

\section{Conclusion}

The microhardness of fcc phase $\mathrm{Cu}_{1-\mathrm{x}}-\mathrm{Zn}_{\mathrm{x}}$ alloys has been measured. The Debye temperatures are calculated using the present hardness values and are compared with Debye temperatures obtained from Kopp-Neumann relation and Xray diffraction studies. Hence, it is concluded that the present values of $\theta_{M}$ for fcc phase $\mathrm{Cu}_{1-\mathrm{x}}-\mathrm{Zn}_{\mathrm{x}}$ alloys agree well with $\theta_{\mathrm{H}}$ and $\theta$ obtained from Eg. 3 and Kopp-Neumann relation respectively. The values of vacancy formation energy $\left(E_{f}\right)$ are estimated for $\mathrm{Cu}_{1-\mathrm{x}}-\mathrm{Zn}_{\mathrm{x}}$ alloys.

\section{References}

[1] Abrahams, S. C. and Hsu, F. S. L. (1975). J. Chem. Phys. 63, 1163.

[2] Pantea, C., Stroe, I., Ledbetter, H., Betts, J. B., Zhao, Y., Daemen, L. L., Cynn, H. and Migliori, A. (2009). Phys. Rev, B80, 024112-1-024112-10.

[3] Pantea, C., Stroe, I., Ledbetter, H., Betts, J. B., Zhao, Y., Daemen, L. L., Cynn, H. and Migliori, A. (2008). J. Phys. Chem. Solids, 69, 211-213.
[4] Deng, X. H., Lu, W., Hu, Y. M. and Gu, H. S. (2009). Physica B 404, 1218-1221.

[5] Plendl, J. N. and Gielisse, P. J. (1965). Applied Optics, 4, 853.

[6] Seigal, E. (1978). Lattice dynamics (Flammarian Sciences, Paris).

[7] Gopi Krishna, N. and Kishan Rao, K. (2004). Bull. of Pure and Appl. Sci. 23, 97-101.

[8] Shankar Narayana, M. (2007). Ph. D thesis, Kakatiya University. Warangal (A. P).

[9] Glyde, H. R. (1967). J. Phys. \& Chem. Solids (GB), 28, 2061.

[10] V. K. Tewary, J. Phys. F (GB) 3, (1973) 704-708.

[11] M. Shankar Narayana and N. Gopi Krishna, Phys. Stat. Sol. (a) 202, No. 14, (2005) 2731-2736.

[12] N. Gopi Krishna, D. B. Sirdeshmukh, B. Rama Rao, B. J. Beandry, and K. A. Gschneidner (Jr), Phys. Stat. Sol. (a) 89, (1985) K37-K38.

[13] D. Singh and Y. P. Varshni, Physical Review B 24, (1981) 4340-4347. 